\title{
Confocal Laser Microscopy of Chondrocytes That Received Gene Transfer Using in vitro Electroporation
}

\author{
MICHIYO TSURU, KENSEI NAGATA, TAKATO UENO*, ATSUO JIMI**, \\ SHINSHI NODA ${ }^{\dagger}$, SHIZUKA IIDA ${ }^{\dagger}$ AND MICHIO SATA \\ Departments of Orthopaedic Surgery, Pathology **, Urology ${ }^{\dagger}$ and Medicine ${ }^{\ddagger}$, School of Medicine and \\ * Research Center for Innovative Cancer Therapy, Kurume University, \\ Kurume 830-0011, Japan
}

\begin{abstract}
Summary: To develop a gene therapy for osteopathies, this study was conducted to establish a method of transferring the BMP gene, a bone formation factor, to cells and administering the cells with BMP expression to patients with osteopathies. Although virus vectors are frequently used for gene transfer, there has been reported a death case of gene therapy using the adenovirus vector. Therefore, various efforts have been made to prevent such complications. In the present study, we used electroporation by which gene transfer can be efficiently performed without inducing severe complications after electric perforation of the cell membrane. Human bone tissues were initially collected intraoperatively, and BMP-2 and Smad4 genes were cloned and integrated into GFP and DsRed plasmid vectors. Using in vitro electroporation, these plasmid vectors were transferred to the cultured chondrocytes (KTN-1) derived from human herniated intervertebral disk. Confocal laser microscopy revealed that the BMP gene was successfully transferred to the nucleus of chondrocytes in the presence of Smad. Since electroporation facilitated human gene transfer to the target cells, gene therapy using electroporation may facilitate individualized treatment for patients.
\end{abstract}

Key words GFP, DsRed, hBMP-2, Smad4, electroporation

\section{INTRODUCTION}

Virus vectors are generally used for transfection. Subsequent death in gene therapy using adenovirus vector was reported, and various efforts have been made to prevent the development of complications. Electroporation, a technique for creating transient pores in the cell membrane for the introduction of exogenous molecules, such as drugs and genes, is well established. Since the first experiments of Neumann and collaborators in 1982, electropulsation of cells in the presence of plasmid DNA has been reported to be an efficient method to induce in vitro gene transfer and expression [1]. Here, we report a physical method, electroporation, by which a gene can be easily introduced with high transfection efficiency and less complications.
MATERIALS AND METHODS

\section{Tissues}

Herniated intervertebral discs obtained from patients with disc herniation were classified as protrusion, extrusion, or as sequestrastion types according to Macnab's classification [2]. The lumbar discs obtained from 23 autopsied cadavers (ranging from 11 to 90 years old) were examined. Herniated intervertebral discs were obtained during surgery from 22 patients (ranging from 18 to 52 years old) with lumbar disc herniation at L4/5. In particular, intervertebral disc with extrusion or sequestration type herniation was subclassified as extruded region or inside region.

The cell line KTN-1 was derived from a human chondrocyte of the central region of the interver- 
tebral disc hernia at L4/5 which was obtained from a 34-year-old Japanese male. He has not received previous lumbar surgery, chemical and irradiation therapy. His surgery was performed on November $11_{\text {th }}$ 1997. The central region of extirpated disc material, which type was subligamentous extruded disc herniation type, was processed for tissue culture immediately after operation. We have examined in detail the conditions of these tissues. Small pieces of intervertebral disc tissue were immersed immediately in fixatives for analysis via electron microscopy and electron microscopic immunohistochemistry. Tissues were fixed in several kinds of fixative to optimize the fixative conditions and to avoid fixative-specific artifacts. The tissue specimen was washed with Hank's balanced salt solution ( $\mathrm{pH}$ 7.4) containing penicillin (100 units/ml) and streptomycin (100 $\mu \mathrm{g} / \mathrm{ml})($ Meiji Seika, Tokyo, Japan) for primary culture. All controlled subjects and patients gave written consent to the study.

\section{Electron microscopy}

Tissue blocks of interest were sequentially fixed with $2.0 \%$ paraformaldehyde $/ 2.5 \%$ glutaraldehyde/PBSem, $1.0 \%$ glutaraldehyde- $0.1 \mathrm{M}$ sodium

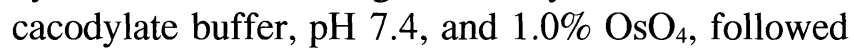
by LR-White (Sigma, St. Louis, MO) embedding. Cultures were fixed with $1.0 \%$ glutaraldehyde and $0.1 \mathrm{M}$ sodium cacodylate buffer, $\mathrm{pH} 7.4$, for $2 \mathrm{hs}$ at 4 ${ }^{\circ} \mathrm{C}$, washed in the same buffer, post-fixed with $1.0 \%$

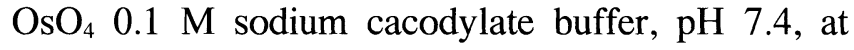
room temperature (RT) for $1 \mathrm{~h}$, and washed twice with $0.1 \mathrm{M}$ sodium cacodylate buffer [3]. The cells were dehydrated in their respective culture dishes by a graded series of alcohols and three changes of absolute ethanol. The culture dishes were immediately infused with $100 \%$ LR-White for $1 \mathrm{~h}$ at RT, followed by $100 \%$ LR-White overnight at $4{ }^{\circ} \mathrm{C}$, and $100 \% \mathrm{LR}-$ White for $1 \mathrm{~h}$ at RT [4]. The culture dishes were cut into culture layers using a scalpel. The culture layer squares in the plane of the dish were assembled into a LR-White block using glue. Ultrathin sections were cut at $90 \mathrm{~nm}$, stained with $2 \%$ uranyl acetate and Reynold's lead citrate, and viewed via a JEM2000EX electron microscope at $100 \mathrm{kV}$ [5].

\section{Established cell line KTN-1}

The tissue specimens were minced into small pieces, dispersed with $0.1 \%$ collagenase (Nitta Gelatin Inc, Osaka, Japan), 0.005\% DNase (Sigma, St.Louis, MO) and $0.002 \%$ hyaluronidase (Sigma, St. Louis, MO) in Dulbecco's Modified Eagle Medium
pH 7.4 (Life Technologies, Grand Island, NY), incubated for $30 \mathrm{~min}$ at $37^{\circ} \mathrm{C}$, and centrifuged at $250 \mathrm{G}$ for $5 \mathrm{~min}$. The cells were suspended in $5 \mathrm{ml}$ of $2 \mathrm{mM}$ EDTA in $\mathrm{Ca}^{2+}$ and $\mathrm{Mg}^{2+}$ free phosphate buffered saline and incubated for $15 \mathrm{~min}$ at $37{ }^{\circ} \mathrm{C}$. After centrifugation, the cells were resuspended in $0.2 \%$ collagenase in Dulbecco's Modified Eagle medium,

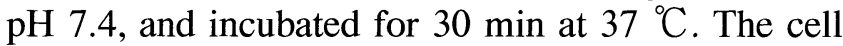
suspension was then filtered through a mesh and centrifuged again. The cell pellet was finally suspended in Dulbecco's Modified Eagle Medium supplemented with penicillin and streptomycin and then seeded on a petri dish (Iwaki Glass, Tokyo, Japan) [6].

\section{Cloning of human BMP-2 and Smad4 cDNA}

BMP-2 and Smad4 mRNA was induced in human bone tissue as described previously. Total RNA of the bone sample was isolated by Isogen (Nippon Gene, Tokyo, Japan) and used for synthesis of firststrand human BMP-2 and Smad4 cDNA using Superscript II RNase $\mathrm{H}$ reverse transcriptase (RT; Life Technologies, Rockville, MD). For PCR analysis, cDNA was amplified in $50 \mu \mathrm{l}$ of Taq polymerase buffer containing 1.25 U Taq DNA polymerase (TaKaRa Ex Taq; Takara Bionedicals, Tokyo, Japan), $0.2 \mu \mathrm{M}$ of each primer, and $0.2 \mathrm{mM}$ of each dNTP. A thermal cycle of $95{ }^{\circ} \mathrm{C}(30 \mathrm{~s}), 58{ }^{\circ} \mathrm{C}(30 \mathrm{~s}), 72{ }^{\circ} \mathrm{C}(1$ min 30s), was performed using a program of 27 cycles for BMP-2. Smad4, performed using for PCR reaction, was repeated for 27 cycles at $55^{\circ} \mathrm{C}(30 \mathrm{~s})$ of annealing. The amplified products were separated by electrophoresis on a $1 \%$ agarose gel. Primer pairs used for murine BMP-2 5'-GCTGTACTAGCGACACCCAC-3'(upper) and 5'TCATAAAACCTGCAACAGCCAACTCG-3'(lower) [7], and for Smad4 5'-GGCCTGATCTTCACAAAA-3' (upper) and 5'AGGCTGACTTGTGGAAG-3'(lower) [8]. Predicted size of the each fragment is 770 and 372 bps, respectively. The PCR product was ligated into a TA cloning vector (Invitrogen, San Diego, CA) using the manufacturer's recommended protocol. The clones that contained inserts (white clones) were selected for minipreparation and digested with EcoR1 (Fig. 1).

\section{Plasmid vectors}

The cDNA of human BMP-2 was inserted into pEGFP-C2 vector (CLONTECH) [9]. The DsRed coding sequence was excised from the pDsRed1-N1 plasmid (CLONTECH) and inserted into the cDNA of human Smad4. Plasmids were grown in Escherichia coli DH5 $\alpha$ cells, and prepared with a Qiagen EndoFree plasmid Giga kit (Qiagen $\mathrm{GmbH}$, 
Hilden, Germany). The quantity and quality of plasmids were assessed by measuring optical density at 260 and $280 \mathrm{~nm}$. Immediately before injection, the DNA was diluted in phosphate-buffered saline (PBS) to $1.0 \mu \mathrm{g} / \mu \mathrm{l}$.

\section{Electric pulse delivery and electrodes}

We performed in vitro electroporation according to the following conditions. Electric pulses were delivered by an electric pulse generator (SQUARE ELECTROPORATOR/CUY21 TOKIWA). Electroporation with eight $20 \mathrm{~V}, 30 \mathrm{~V}$ and $50 \mathrm{~V}$ electric pulses showed highly efficient gene transfer, as reported for BMP-2 and Smad4 in KTN-1.

\section{Single-photon confcal microscopy}

A standard beam scanning microscopy (ISMGB200; Olympus, Tokyo, Japan) with adjustable bandwidths of the detected fluorescence wavelengths was used. Simultaneous excitation was achieved by the 488 and $568 \mathrm{~nm}$ lines from an ArKr-laser. EGFP fluorescence was detected from 490 to $540 \mathrm{~nm}$ and

\section{TA cloning}

\section{M}

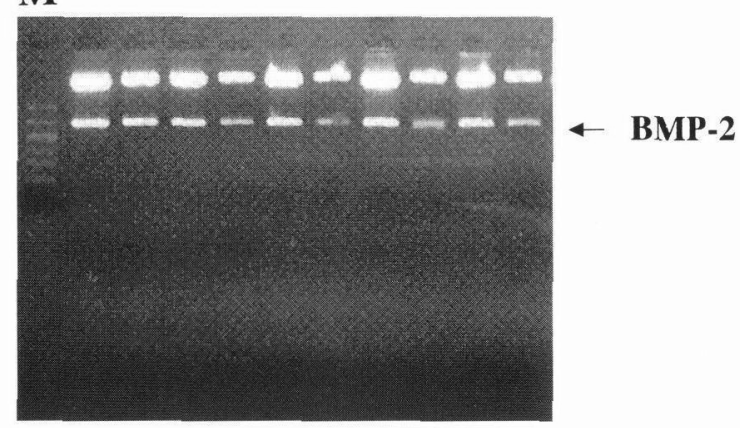

M

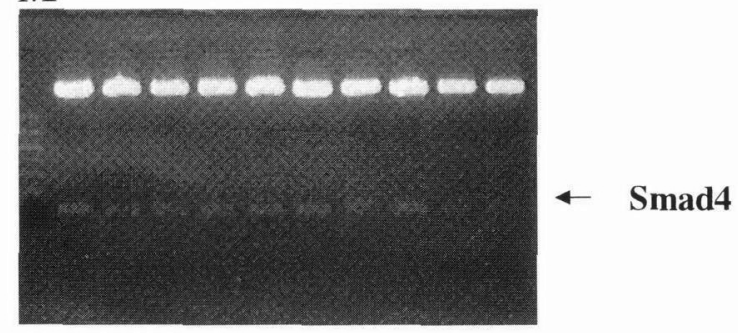

Fig. 1. Subcloning of the PCR products. The $5 \mu 1$ of the second round PCR products were ligated into the TA cloning vector as described in Materials and Methods. Clones with inserts were randomly picked up for miniprep analysis. concurrently the DsRed emission from 620 to $670 \mathrm{~nm}$.

\section{Two-photon microscopy}

For two-photon imaging we used a converted commercial beamscanning microscope (Olympus) employing a mode-locked Ti: sapphire Laser pumped by an $8 \mathrm{~W}$ argon-ion laser, tuned to $925 \mathrm{~nm}$. To separate the infrared excitation from the fluorescence we used a $660 \mathrm{~nm}$ long-pass dichroic mirror mounted at a $45^{\circ}$ angle to the beam. After deflection the fluorescence light was further split by a $540 \mathrm{~nm}$ shortpass dichroic mirror and directed to two photomultipliers. The red sensitive PM R6357 was utilized for DsRed detection. To biock residual EGFP fluorescence a $590 \mathrm{~nm}$ longpass filter was placed in front of the photomultiplier opening. To further prevent residual laser light from being detected, the backpropagating light passed IR-blocking filters. No pinholes were used; the detection was performed in a non-descanned mode. The PM for DsRed was detected using the photon microscopy with $1064 \mathrm{~nm}$ excitation, which was the same setup as for FLIM. However, the laser was changed to Nd: Glass laser. The laser delivered $-200 \mathrm{fs}$ pulses at a repetition rate of $-120 \mathrm{MHz}$. The power of the excitation light in the focus was about $1 \mathrm{~mW}$.

\section{RESULTS}

When herniated intervertebral disc-derived human chondrocytes were cultured under normal homeostatic conditions, spherical nuclei and the development of rough-surfaced endoplasmic reticula were observed under an electron microscope (Fig. 2). Using in vitro electroporation, these plasmid vectors

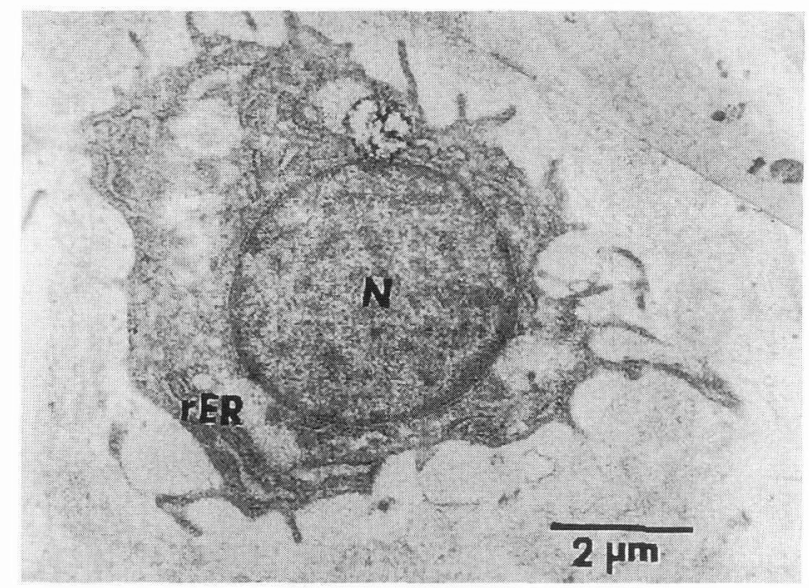

Fig. 2. Electron micrograph cultured chondrocytes derived from human intervertebral disc herniation (A). (bar=2 $\mu \mathrm{m})$. KTN-1. 
were transferred to the cultured chondrocytes (KTN1) derived from human herniated intervertebral disc. Confocal laser microscopy revealed that the BMP gene was successfully transferred to the nucleus of chondrocytes in the presence of Smad (Fig. 3). In addition, Figure 4 shows typical confocal laser scanning microscopic images of GFP-BMP-2 and DsRedSmad4, electroporation with eight $20 \mathrm{~V}$.

BMP-2 and Smad4 were cloned from human bone tissue, and plasmid vectors were constructed by inserting the cloned genes into GFP and DsRed. Using electroporation, the plasmid vectors were introduced into human herniated intervertebral disc-

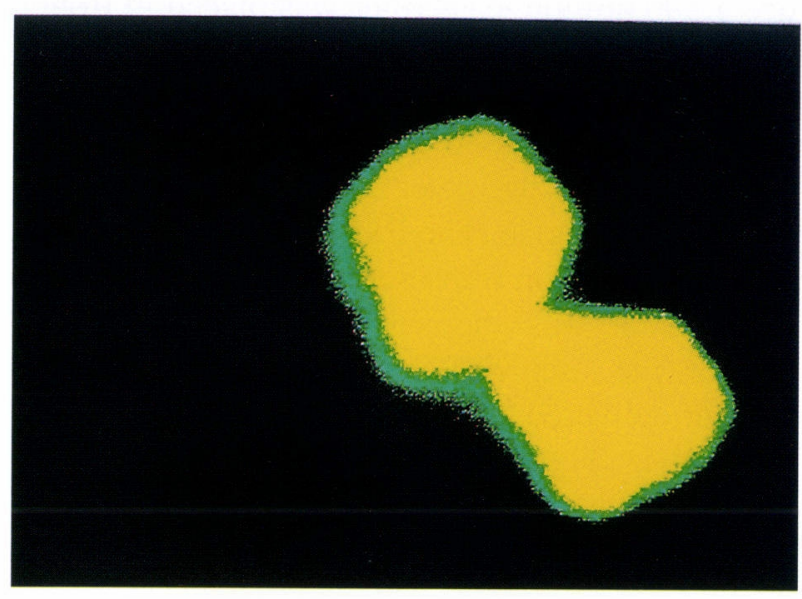

Fig. 3. Confocal laser scanning microscopic images of GFP-BMP-2 and DsRed-Smad4, electroporation with eight $50 \mathrm{~V}$.

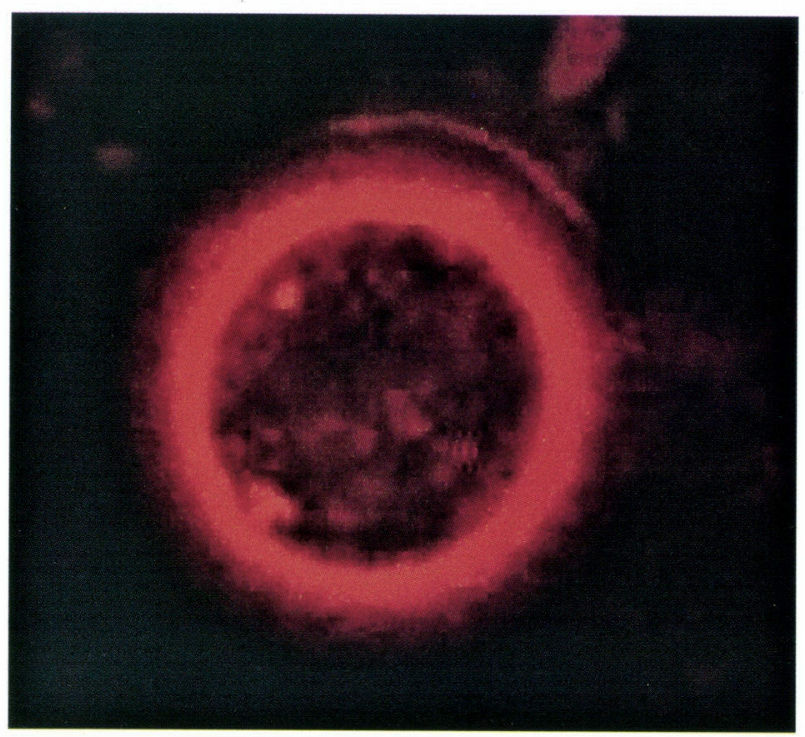

Fig. 4. Confocal laser scanning microscopic images of GFP-BMP-2 and DsRed-Smad4, electroporation with eight $20 \mathrm{~V}$. derived chondrocytes that we established, and the presence of BMP complex in the nuclei was confirmed under a confocal laser microscope. We also observed that the transfection efficiency of the plasmid vectors changed when the conditions of electroporation changed.

\section{DISCUSSION}

For the purpose of gene therapy, we established a method of introducing a gene into cells to develop a new therapy for bone diseases by administering transgenic cells and expressing osteogenic factor BMP in the patient. Electroporation perforates the cell membrane and simultaneously introduces genes into the cells. Since plasmid vectors are circular and negatively charged, when a voltage is applied, plasmid vectors migrate into the cells at the anode. If the electric field is not excessive, the perforations are repaired after the electric field is stopped, and transcription of the plasmid vectors that entered the cells initiates. Electroporation is a useful method for safe transfection of a target gene into cells, but the conditions may be problematic. However, electroporation is better than the lipofectin method that damages the cells. TGF- $\beta$ is a factor that inhibits cell growth, epithelial cell growth, in particular. BMP was identified as a factor that induces osteogenesis and chondrogenesis. Later, BMP was clarified to have an important function in morphogenesis in the developmental process. TGF- $\beta$ and BMP, together

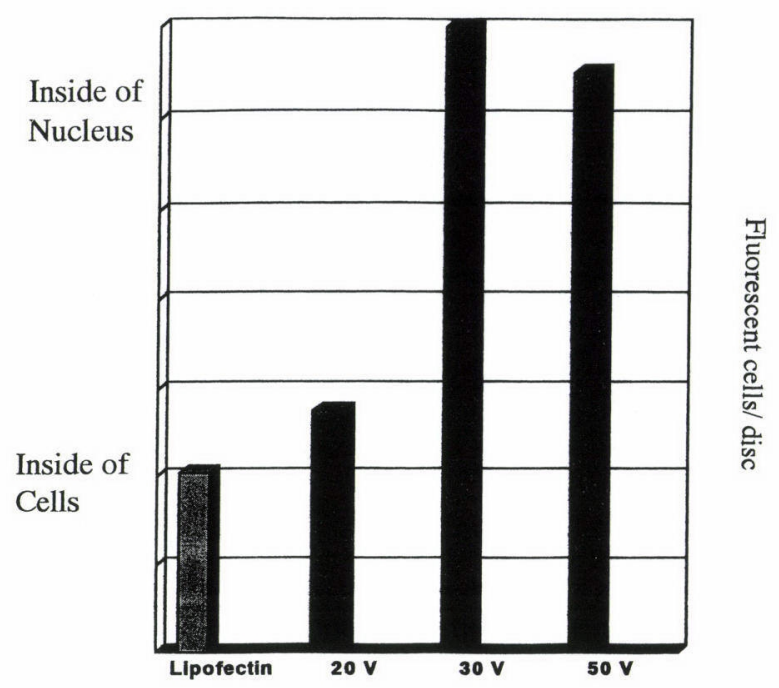

Fig. 5. Confocal laser microscopy of chondrocytes that received gene transfer using in vitro electroporation comparative study of the lipofectin. 
with activin, form the TGF- $\beta$ superfamily. When TGF- $\beta /$ BMP binds to specific receptors, signal transduction molecule Smad is activated. Eight types of Smad have been found to date, and are divided into three subgroups: R-Smad, Co-Smad, and Inhibitory Smad. R-Smad is phosphorylated by the activated receptor to an active form, which forms a complex with Co-Smad and enters the nucleus. The Smad complex binds to DNA directly or via binding to a transcription factor, and participates in the regulation of target gene transcription $[10,11]$. We introduced BMP-2 via Smad4 into the nuclei of human herniated intervertebral disc-derived chondrocytes using electroporation.

\section{CONCLUSION}

Confocal laser microscopy revealed that the BMP gene was successfully transferred to the nucleus of chondrocytes in the presence of Smad using electroporation.

Electroporation may become applicable to the clinical treatment in the future because of selectivity of vectors and maintenance of long-term gene expression.

ACKNOWLEDGMENTS: In preparing this study, the authors had many discussions with Takeshi Imamura, MD (The Cancer Institute, Tokyo). His contributions to our paper have been great and the authors take pleasure in acknowledging the important part played by him. The authors wish to express their gratitude to Prof. Mitsuaki Yoshizuka (Department of Anatomy, Kurume University School of Medicine) for frequent, stimulating and helpful discussions. Several helpful discussions with Mr. K Yoshida and Mrs. M Nagao, Mrs. Y Kawahara, Miss. R Matsuda, Miss. C Hijikata, Miss. C Hashimoto and Miss. R Yamagata (Department of Orthopaedic Surgery, Kurume University School of Medicine) are gratefully acknowledged. Thanks are also due to the many colleagues with whom they have discussed this problem.

\section{REFERENCES}

1. Neumann E, Schaefer-Ridder M, and Wang Y. Gene transfer into mouse lyoma cells by electroporation in high electric fields. EMBO J 1982; 1:841-845.

2. Macnab I. Backache, Williams \& Wilkins, Baltimore, pp. 91-95, 1977.

3. Grutzkau A, Kruger-Krasagakes S, Kogel H, and Moller A. Detection of intracellular interleukin-8 in human mast cells: Flow-cytometry as a guide for immunoelectron microscopy. J Histochem Cytochem 1997; 45:935-945.

4. Sobrl RA, Hinojoza JR, Maeda A, and Chen M. Endothelial cell integrin laminin receptor expression in multiple sclerosis lesions. Am J Physiol 1998; 153:405415 .

5. Kuhn H. A simple method for the preparation of cell cultures for ultrastructural investigation. J Histochem Cytochem 1981; 29:84-86.

6. Funakoshi A, Tateishi K, Tsuru M, and Jimi A. Acetylcholine regulates pancreastatin secretion from the human pancreastatin-producing cell line (QGP-1N). J Clin E \& M 1991; 73:151-155.

7. Wozney JM, Rosen V, Celeste AJ, and Mitsock LM. Novel regulators of bone formation: Molecular clones and activities. Science 1988; 242:1528-1534.

8. Villanueva A, Garcia C, Paules $A B$, and Vicente $M$. Disruption of the antiproliferative TGF- $\beta$ signaling pathways in human pancreatic cancer cells. Oncogene 1998; 17:1969-1978.

9. Harada M, Sakisaka S, Kawaguchi T, and Kimura R. Copper does not alter the intracellular distribution of ATP7B, a copper-transporting ATPase. Biochemical and Biophysical Research Communications 2000; 275:871876.

10. Imamura T, Takase M, and Nishihara A. Smad6 inhibits signalling by the TGF-beta superfamily. Nature 1997; 389:622-626.

11. Savage C, Das P, and Finelli AL. Caenorhabditis elegans genes sma-2, sma-3 and sma-4 define a novel conserved family of transforming growth factor $\beta$ pathway components. Proc Natl Acad Sci USA 1996; 93:790-794. 